\title{
Semanario La Argentina Weekly La Argentina
}

En esta oportunidad, Ratón de hemeroteca y videoteca propone revisitar las amarillentas páginas de La Argentina, el pequeño periódico femenino que circulara durante la época en la que gobernó la provincia de Buenos Aires el brigadier general Juan Manuel de Rosas. Para esto, retomaremos algunos conceptos vertidos en el libro La Argentina 1830-1831. Edición facsimilar (Díaz, 2011) en el que se ofrece la reproducción facsimilar del periódico.

El semanario La Argentina apareció el 31 de octubre de 1830 y fue el primer periódico femenino de nuestro territorio. La publicación posee una denominación que podríamos definir como ambivalente, ya que puede remitir tanto a la República Argentina, colectivo de identificación usado en forma frecuente en sus columnas, como a la mujer argentina. Para ese entonces, en nuestro territorio ya habían circulado distintos órganos gráficos que llevaban esa denominación, como complemento adjetivo o como gentilicio, por lo que un detalle no menor lo constituye la omisión efectuada por Ángel Rosenblat (1964), quien no consigna al medio La Argentina en su exhaustiva indagación acerca de los orígenes del nombre de nuestro país.

La Argentina conmovería profundamente a la opinión pública, dado que nunca antes un periódico había elegido a la mujer como receptora principal de su mensaje. El semanario abordó temáticas tales como la política, la moda, la educación, la sociabilidad, entre otras muchas. Con todo, tuvo otros temas que cuestionar y lo hizo con la agudeza que lo caracterizaría al ser portavoz de las mujeres rioplatenses, pero con el valor agregado de que entre sus objetivos estaba el de gravitar en la esfera pública de forma protagónica. El semanario era editado los domingos por la imprenta Republicana —ubicada en la calle Suipacha N. ${ }^{\circ} 19-$, una de las seis imprentas radicadas en la ciudad de Buenos Aires por aquellos años. 
Más allá de los intereses esgrimidos desde sus páginas, este papel público ha generado discusiones en relación con su condición, es decir, con la posibilidad de ser considerado un «periódico femenino». Por caso, Lily Sosa de Newton (2000) no lo reconoce en su historia del periodismo femenino. Otros, si bien lo mencionan, lo subestiman por entender —a nuestro juicio, erróneamente- que su director era un hombre (Auza, 1998, 2004; Batticuore, 2005), ${ }^{1}$ omitiendo de este modo un aspecto importantísimo del carácter del medio, que sin duda alguna estaba destinado a un público femenino. En el caso de Néstor Auza (1988), este entiende al periodismo femenino como a aquel escrito por mujeres que, en términos amplios, puede clasificarse de literario, aunque incluye a otras producciones referidas a «temas culturales y sociales desde una perspectiva exclusivamente femenina» (p. 10). Esta definición excluiría al semanario que analizamos. Sin embargo, si repensamos la categoría de periodismo femenino y ampliamos esa concepción acotada en relación con los contenidos y con los géneros —como por caso, el conjunto de producciones dirigidas a un público predominantemente femenino, no en forma excluyente e independientemente de los contenidos de sus páginas-, podemos incluir perfectamente a La Argentina en esta categoría.

En este punto, creemos mucho más interesante y fructífero decir que La Argentina, más allá de la identidad de quien la orientara, era una publicación eminentemente dirigida a las mujeres, con el valor agregado de que sus páginas, además de ofrecer modas, cartas de lectores, sociabilidad, defensa de consumidores, etcétera, introducirían en el universo femenino la idea de que las mujeres poseían un rol decisivo en la política, pues eran actoras sociales influyentes. Esta convicción profundamente innovadora se explicitaba número a número en la sección «Política» que era la voz institucional del medio. Tales particularidades la diferenciaron nítidamente de su colega La Aljaba (1830-1831), con la que compartía el interés por captar al público femenino.

La Argentina tuvo dos épocas, con 35 ejemplares en total. La primera, del 31 de octubre de 1830 al 15 de mayo de 1831; la segunda, con solo seis entregas, del 12 de junio de 1831 al 17 de julio de ese mismo año. 
La principal meta del periódico se concretaría ya desde la circulación del prospecto, titulado en este caso «Introducción». Allí se podía leer: «Causará novedad una mujer de periodista, pero ha llegado el caso de ensayar, si tenemos influjo. Los hombres están extraviados en su mayor parte, y es preciso traerlos a la razón. Los criticones serán moderados en su censura. Nosotros hablaremos de todo en general sin agraviar a nadie en particular. La República Argentina es nuestro país y sentimos los males de todos. Criticaremos lo que a nuestro juicio merezca censura» (LA, 31/10/1830, p. 2).

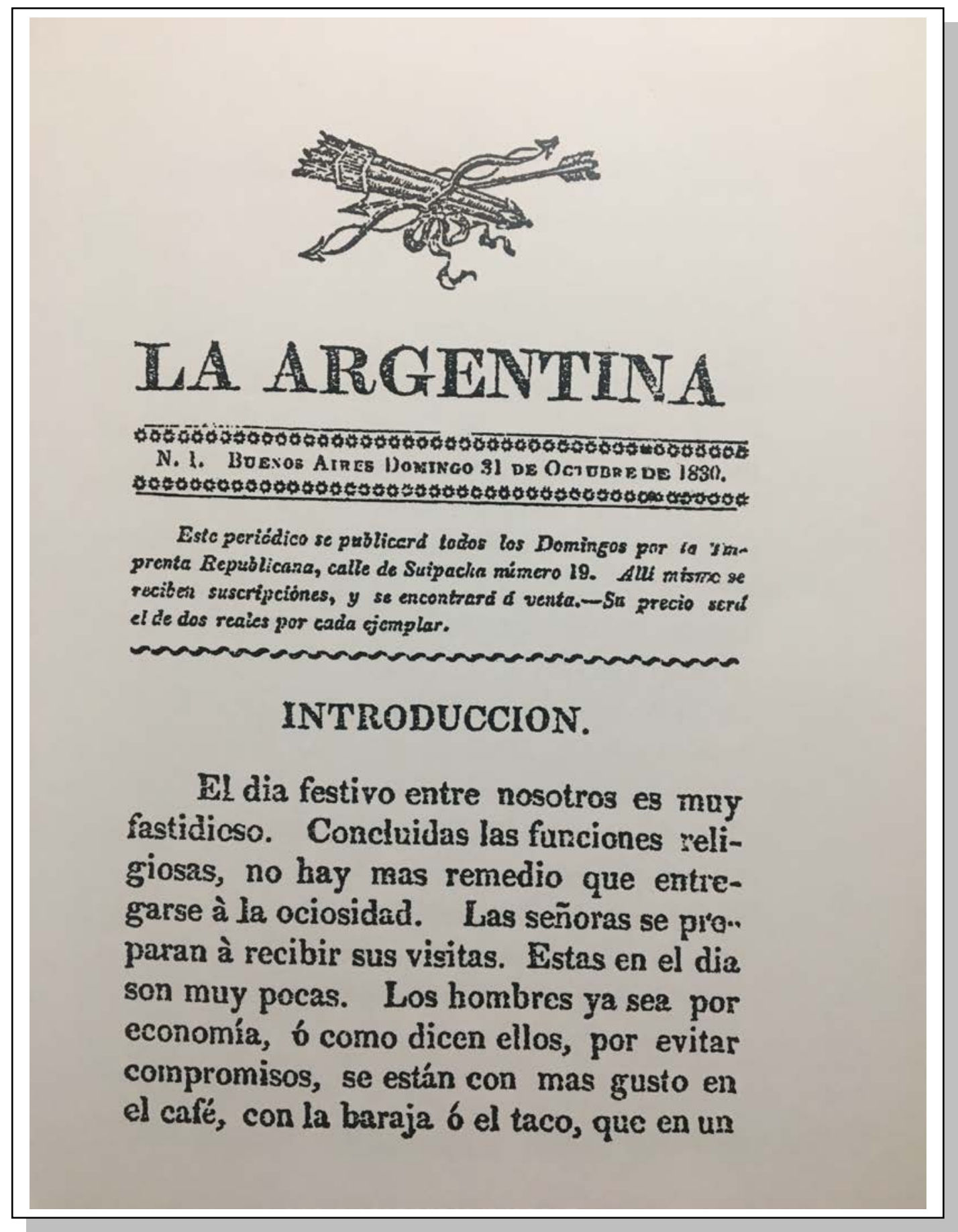

La Argentina, 31 de octubre de 1830, p. 1 


\section{(2)}

estrado al lado de las damas. Para evitar el enfado que ocasiona el no tener que hacer, nos hemos resuelto á escribir un periódico que solamente debe publicarse los Domingos, y si nos es posible conciliar nuestras ocupaciones tambien saldrà los dias festivos. Su forma es nueva de modo que pueda llevarse en el ridículo.

Causará novedad una muger de periodista, pero ha llegado el caso de ens:yar, si tencmos influjo. Los hombres están estraviados on su mayor parte, y es preciso tracrlos à la razon. Los criticones seràn moderados en su censura. Nosotros hablarémos de todo en general sin agraviar à nadie en particular. La República Argentina es nuestro país, y sentimos los males de tados. Criticarémos lo que á nuestro juicio merezca censura. Creemos que lo dicho basta sara prospecto, porque es ocioso prometer mucho sin saber lo que se puede cumplir. 
El periódico femenino propuso a sus lectoras/es una suerte de definición del subsistema de los medios de la época, como una modalidad de presentación innovadora, al tiempo que procuraba establecer una buena relación periodística con sus colegas porteños: «Cinco periódicos son los que se publican en esta ciudad. El Lucero es considerado ministerial. Tiene buen crédito. Es un papel ilustrado. La Gaceta es un recipiente universal. Estos días se ha mostrado un poco iliberal reprobando la Revolución Francesa. Actualmente escribe con mucho juicio. El Tribuno es muy patriota y muy valiente. Su editor es digno de mucha consideración, porque no se para en arrostrar compromisos a favor de la buena causa. El Gaucho y el Torito, siempre de broma, suelen dar algunos malos ratos pero divierten» (LA, 31/10/198o, p. 4).

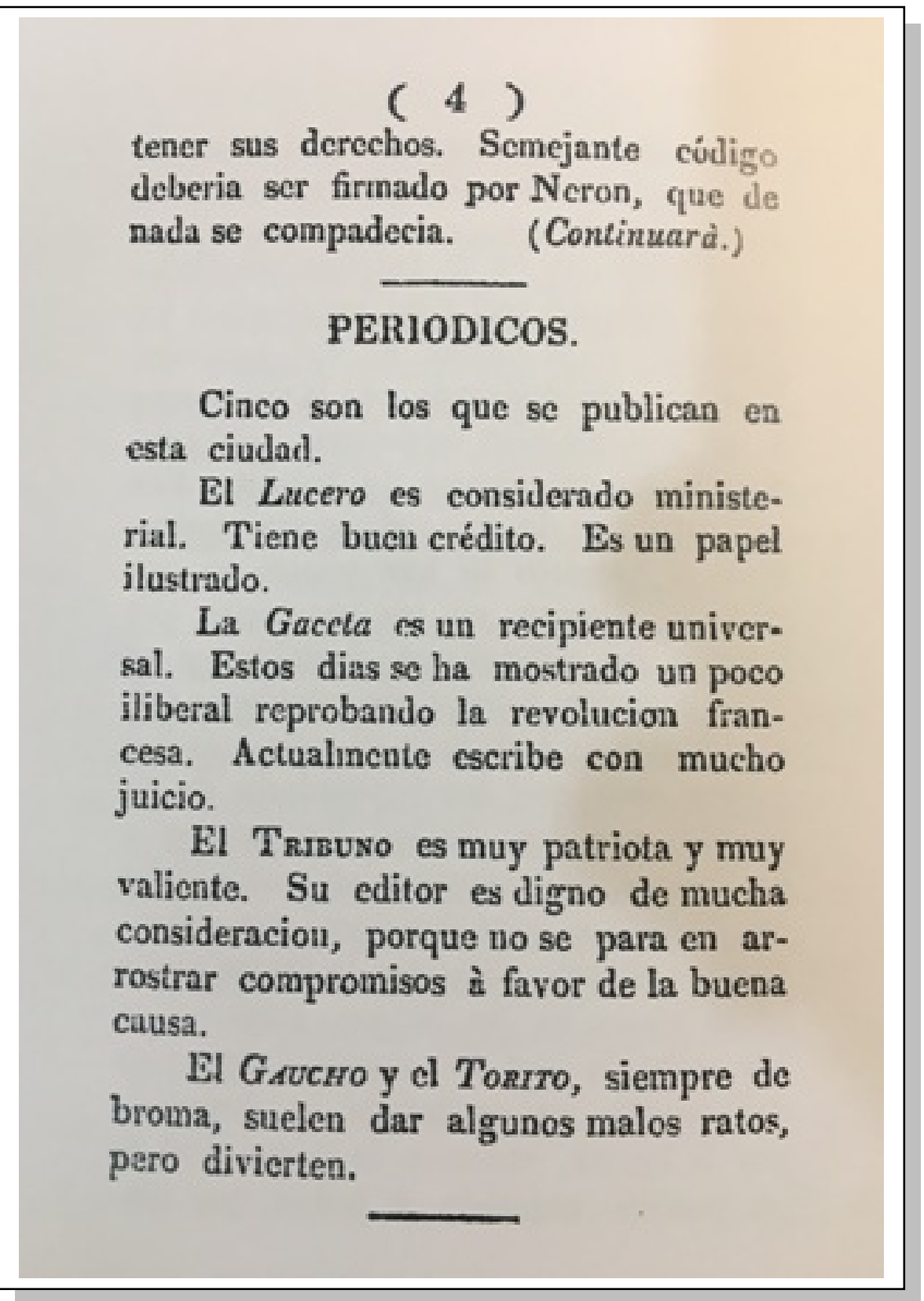

La Argentina, 31 de octubre de 1830, p. 4 
Un rasgo distintivo de la publicación femenina fue que supo inmiscuirse de lleno en temas reservados para los hombres. En tal sentido, resulta interesante rescatar la explicitación de tal particularidad respecto al controvertido tema de contar con una Carta Magna como punto inicial para la organización del país. Esa línea promotora de la discusión se explicitaba, sin eufemismos, en el primer editorial: «Puestas ya en la palestra principiaremos nuestros trabajos, exhortando a los hombres a la calma de sus pasiones. Nuestro país destinado por la naturaleza a ser una mansión de delicias, está convertido en un campo de batalla. Los militares por lo general gente turbulenta e inquieta lo han puesto en ese estado. Ejercen en las provincias del interior un despotismo inaudito y es muy singular cubran sus atentados con el pretexto de constituir el país. Jamás hemos oído que los legisladores de un pueblo sean los fusiles, las espadas y las lanzas. La constitución, como todas las cosas son buenas y duraderas, mientras se quieren. Más por la fuerza nadie hasta ahora se ha hecho amar. Una ley resistida por la mayoría, gravosa por cuanto es respetada, y sostenida por la fuerza, causaría la ruina total de un pueblo enlutado y pobre, por sostener sus derechos» (LA, 31/10/198o, p. 3-4).

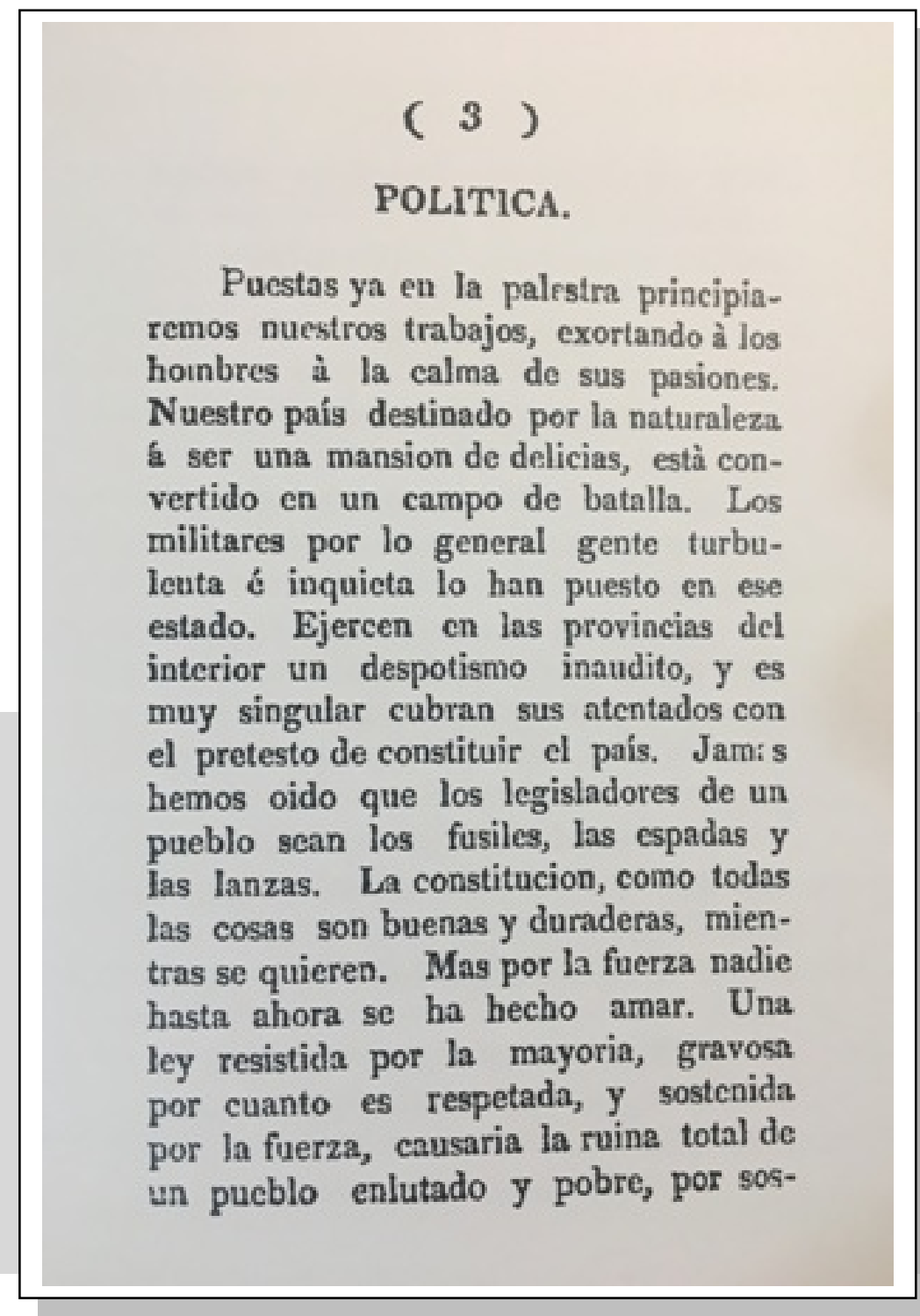

La Argentina, 31 de octubre de 1830, p. 3 


\section{Polémica con La Aljaba}

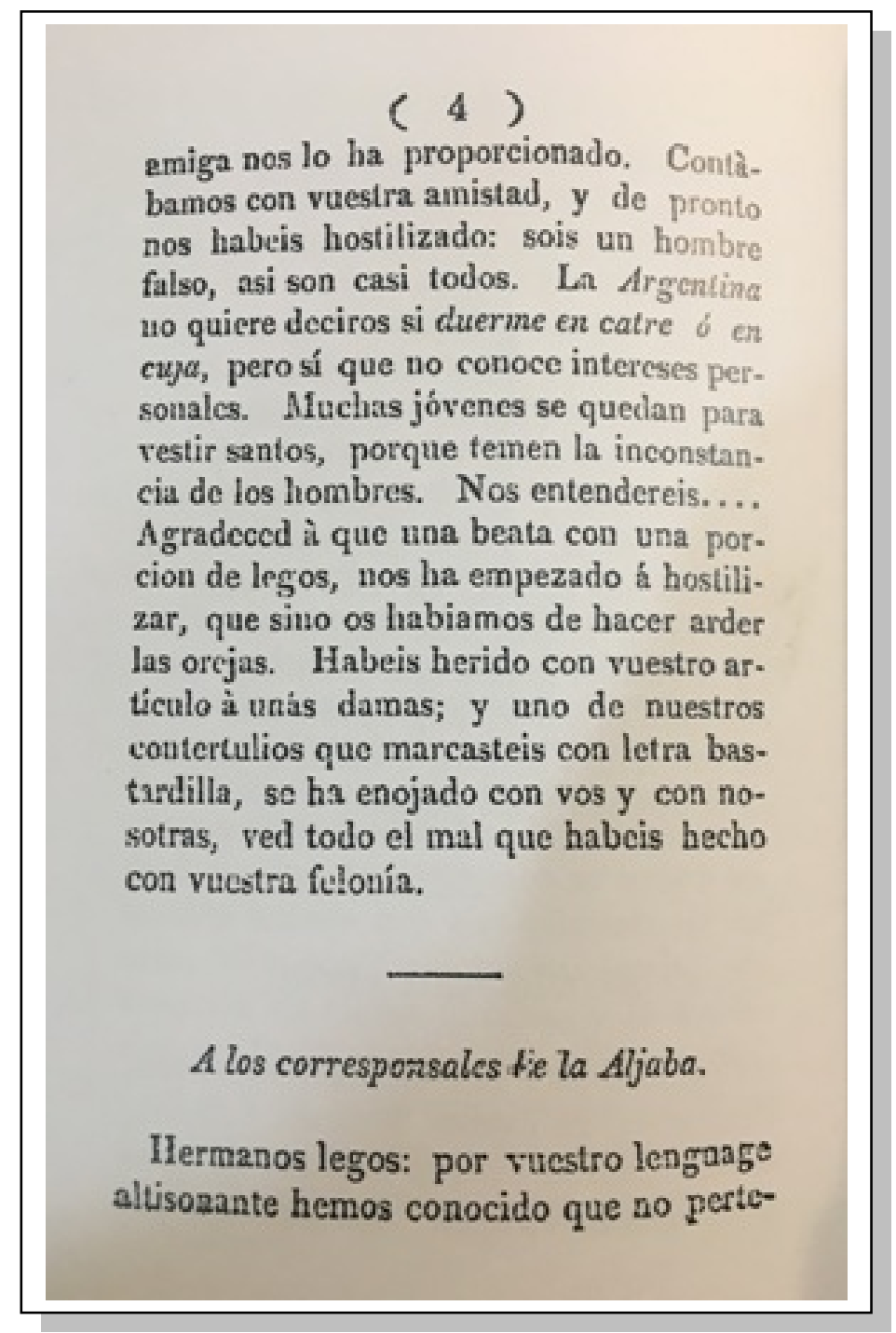

La Argentina, 12 de diciembre de 1830, p. 4

En este punto, resulta útil rescatar un artículo que La Argentina destinaba al diario El Clasificador, en el que se quejaba de su traición. Aunque, como se verá, optaba por polemizar con el bisemanario femenino: «Agradeced a que una beata con una porción de legos, nos ha empezado a hostilizar, que si no os habíamos de hacer arder las orejas» (LA, 12/12/1830, p. 4). Sin duda alguna, aludía al suelto rubricado por los esposos.

No resulta extraño, entonces, que la respuesta por parte de La Argentina no se hiciera esperar y que con un tono cargado de ironía sugiriera: «Hermanos legos: por vuestro lenguaje altisonante hemos conocido que no pertenecéis a este mundo y con gente de la otra vida no queremos tener negocios. Seguid con vuestra jerga y dejadnos tranquilas, que con nadie queremos guerra. Hemos oído vuestros sermones, y no nos hemos convertido. Continuad predicando que con el tiempo todo se consigue, menos lo que vosotros solicitáis» (LA, 12/12/1830, pp. 4-5). 


\section{( 5 )}

neceis à este mundo; y con gente de la otra vida no queremos tener negocios. Seguid con vuestra gerga y dejadnos tranquilas, que con nadie queremos guerra. Hemos oido vuestros sermones, y no nos hemos convertido. Continuad predicando que con el tiempo todo se consigue, menos lo que vosotros solicitais.

\section{LA GUERRA.}

ODA.

Por oprimir al mundo,

El déspota proclama

La guerra asoladora;

Que tantos males causa.

Atónitos los hombres

En su ruina se afanan,

Y corren á matarse

Al grito del alarma.

El pueblo pesaroso.

La Argentina, 12 de diciembre de 1830, p. 5 


\section{Dificultades de la profesión}

\section{de periodistas}

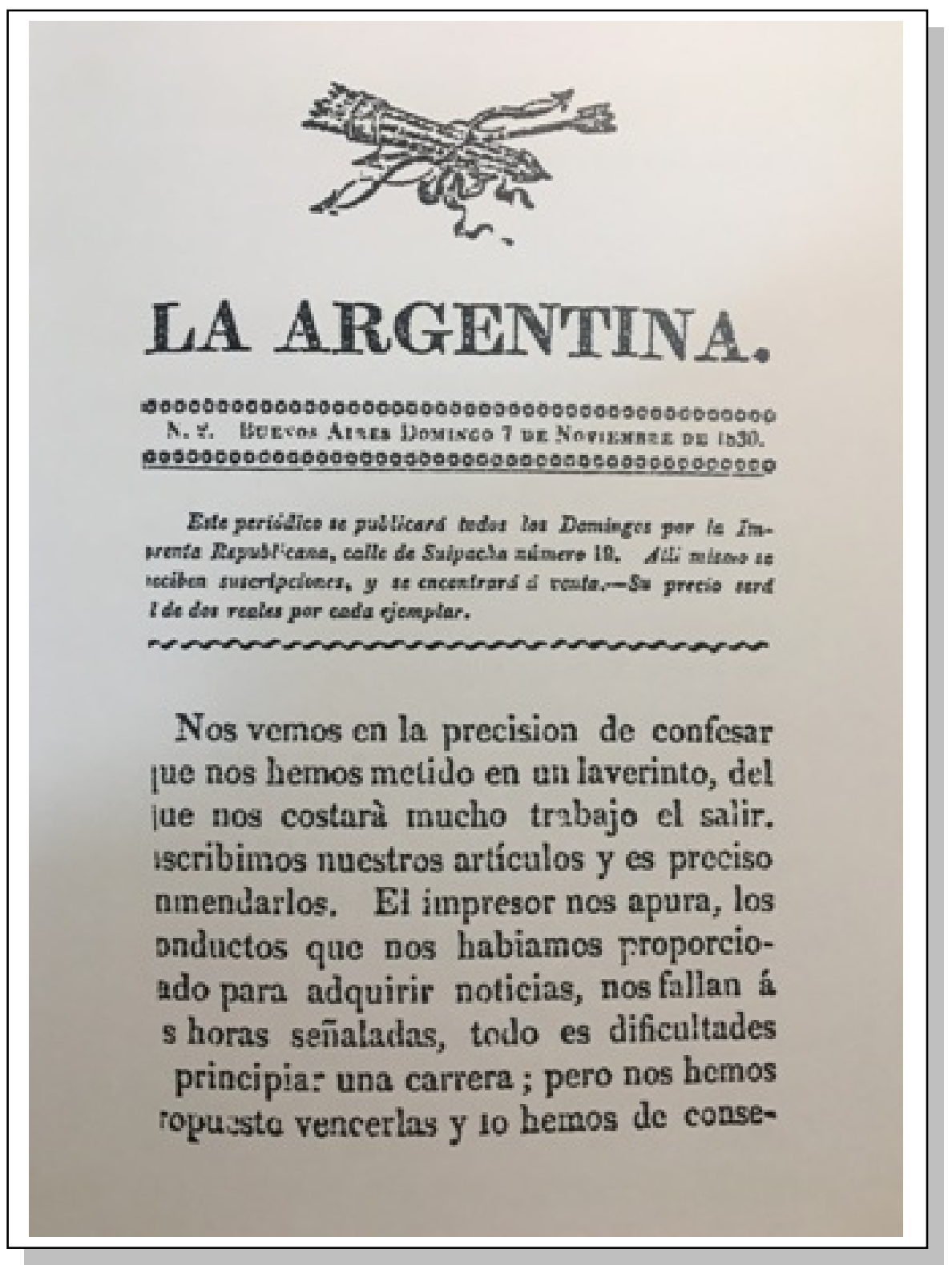

La Argentina, 7 de noviembre de 1830, p. 1

«Nos vemos en la precisión de confesar que nos hemos metido en un laberinto, del que nos costará mucho trabajo salir. Escribimos nuestros artículos y es preciso enmendarlo. El impresor nos apura, los conductos que nos habíamos proporcionado para adquirir noticias, nos fallan a las horas señaladas, todo es dificultades al principiar una carrera; pero nos hemos propuesto vencerlas y lo hemos de conseguir. Con razón los hombres ponderan tanto sus trabajos» (LA, 7/11/1830, pp. 1-2). 
«Tenemos que confesar un error, y es el habernos metido a periodistas. ¡Qué mortificación Dios mío! Todo el día pensando en los artículos que hemos de publicar. Borrando papel, peleándonos con el impresor porque nos apura, porque no corrige bien las pruebas. ¡Qué infierno señor! No es esto lo más malo. Ya viene un marido y se enoja, nos reprende con crueldad, los mozos también se incomodan, otros nos dicen machos, en suma nadie agradece nuestros trabajos. ¿Pero desistiremos nosotras de la empresa? Ya no puede ser, estamos comprometidas, y es preciso seguir. La inconstancia se hizo para los hombres. Nosotras somos firmes en nuestras resoluciones. ¿Quién nos quita el gusto de decirles cuatro verdades y de amenazar a los maridos que no se conduzcan bien con sus mujeres y a los solteros que piensen andar embromando? Esto solo nos compensa de nuestras incomodidades [...]. Nosotras hemos de triunfar. Nuestro periódico ha de seguir a pesar de todo y cada día lo hemos de ir mejorando. Algunos puede ser que tengan sus malos ratos, pero nada nos importa. La verdad por delante y fuera penas y cuidados» (LA, 24/4/1831, pp. 3-4).

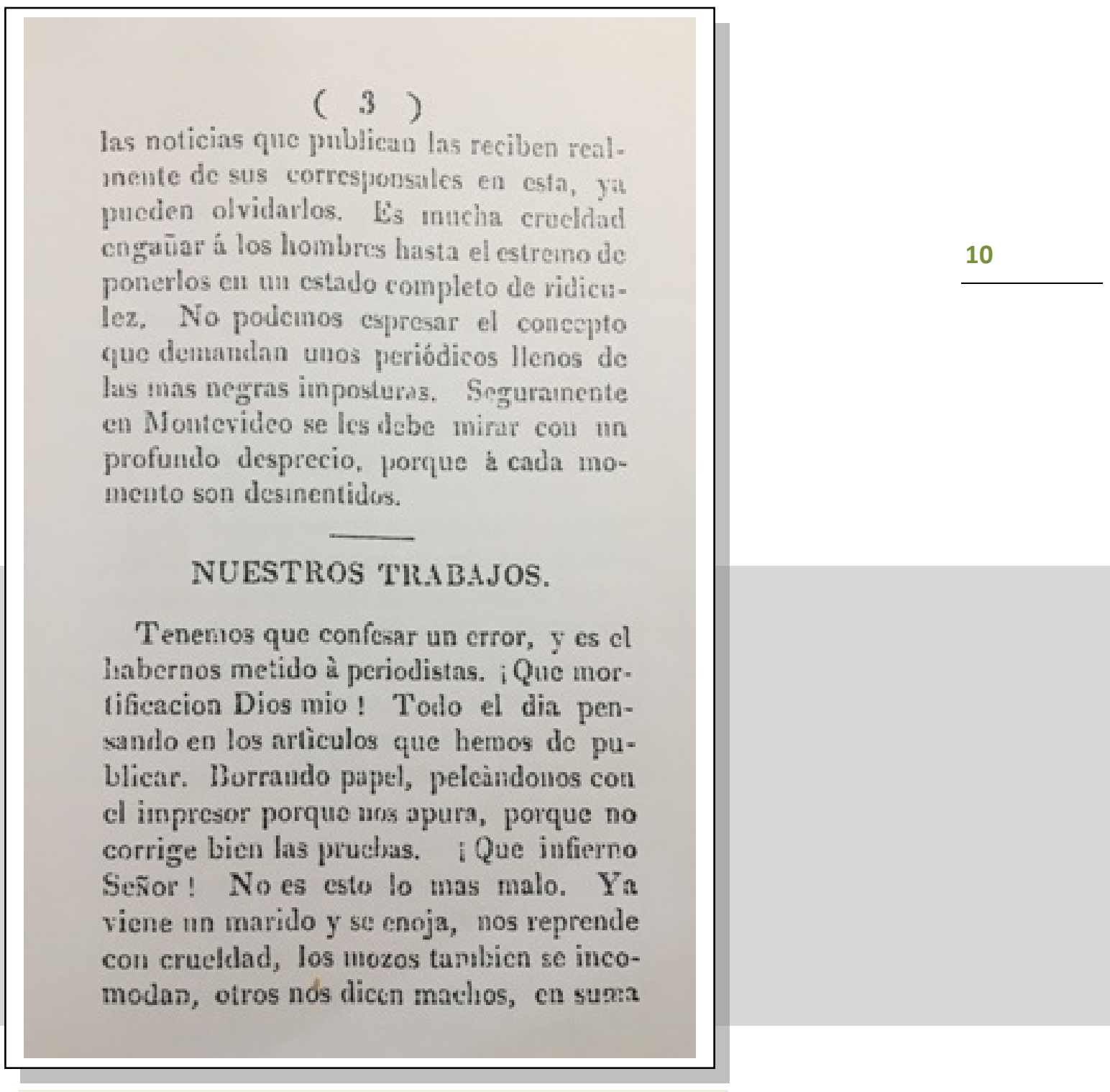

La Argentina, 24 de abril de 1831, p. 3 


\section{Igualdad de sexo!}

\begin{abstract}
( 10$)$
recuerdos lisungeros, dissto que no se: considican obligtos al reconocimiento. A nosotres nos ligun las rulaciones de nathtio corazon. Ioni hombres para scntirlas neccitan vivir en una continua inquietul, y como esian sconuros de nuexin ex siva somibilidad. Sulen siempie con sus caprichos. Es preciso que cimentemos nuestro inperio sobre bases muy rales pard convencerlos que no necesitamus su proteccion. $\Lambda$ si les doinaremos esc orgullo iusoportable, y cuancio ellus se convenzan de que somos iguales, rcecuoceran la influencia que tienen numstros atractivos sobre ese ridiculo poder de gaz tanto se envanecen.
\end{abstract}

\section{TEATRO.}

En la semana pasada se han cxhibido dos piczas nuevae, y los repelidas. Nos ha hecho suepirur la velocidad con que corre la temporadn. Los actores se hän dezcmpeñado perfectumente, y

La Argentina, 9 de abril de 1831, p. 10

A propósito de las relaciones entre hombres y mujeres, La Argentina supo publicar innumerables artículos referidos a la utópica idea para el período de que ambos sexos mantuvieran un pie de igualdad en la sociedad de la época. En tal sentido, resulta interesante rescatar la ocasión en la que una redactora expresó: «... los hombres [...]. Salen siempre con sus caprichos. Es preciso que cimentemos nuestro imperio sobre bases muy reales para convencerlos que no necesitamos su protección. Así les domaremos ese orgullo insoportable y cuando ellos se convenzan de que somos iguales reconocerán la influencia que tienen nuestros atractivos sobre ese ridículo poder de que tanto se envanecen» (LA, 9/4/1831, p. 10). 
La igualdad entre los sexos es un reclamo que las mujeres han sostenido desde tiempos inmemoriales. En La Argentina, la problemática fue puesta en el centro de la escena a través de una cuestión religiosa. Efectivamente, en una oportunidad, refiriéndose a la necesidad del amor en el matrimonio se podían leer estas contundentes reflexiones: «El cristianismo ha sacado a las mujeres de un estado de esclavitud. La base de esta religión sagrada y admirable, es la igualdad ante los ojos de su divino autor. Ella mantiene la igualdad de derechos sobre la tierra, de consiguiente esta justicia divina, rechaza todo género de privilegios, y principalmente el que se funda en la fuerza. A pesar de todo, las mujeres son esclavas de ciertas preocupaciones que combinadas con la libertad que la sociedad les ha dejado, han ocasionado muchos males. Resueltas a probar hasta la evidencia que ningún título tienen los hombres, estos tiranos del mundo, para deprimir a nuestro sexo, volveremos sobre este particular que debe ser tratado muy detenidamente» (LA, 20/2/1831, pp. 10-11).

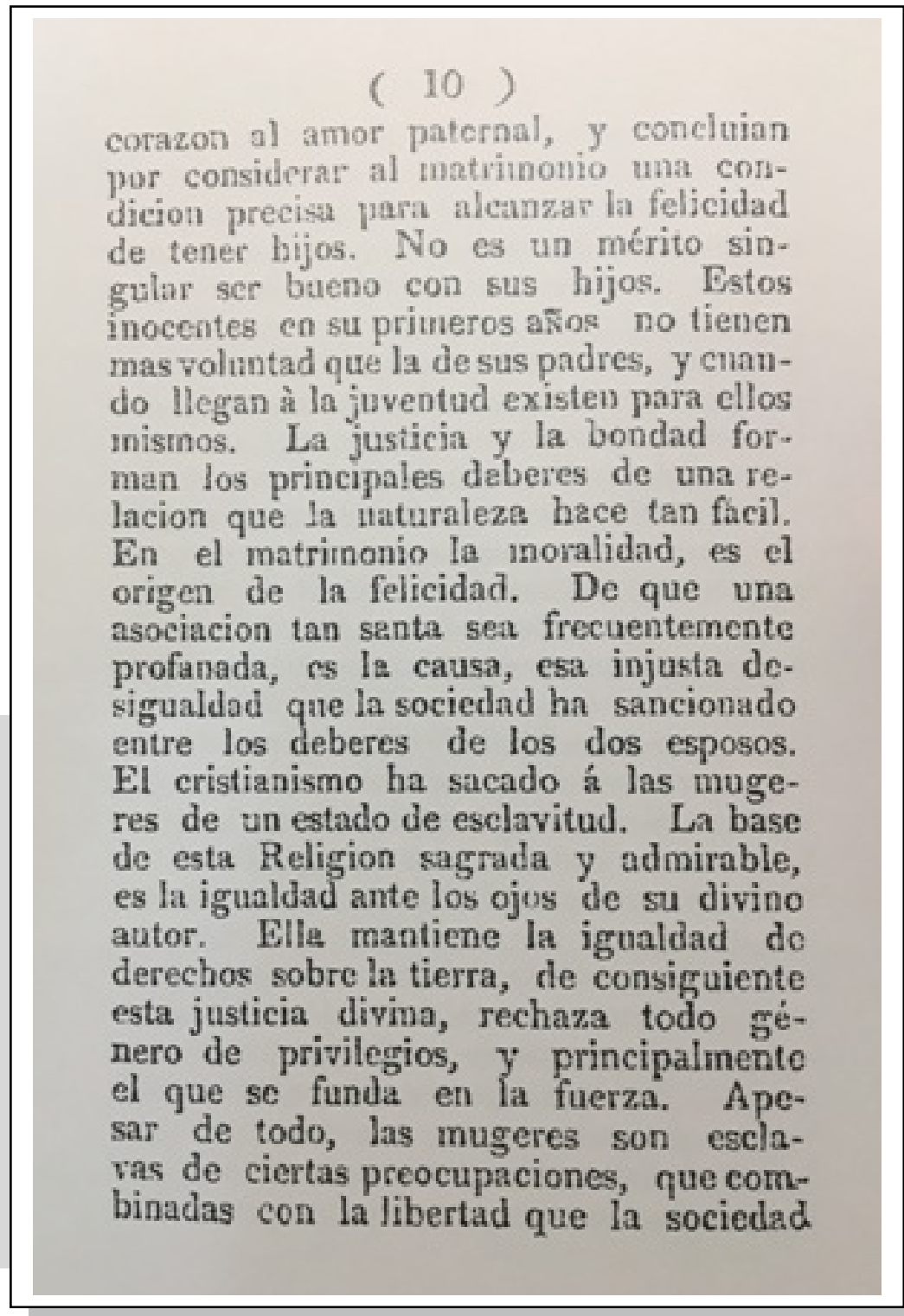

La Argentina, 20 de febrero de 1831, p. 10 
Tal cual lo declararon en el número subsiguiente, la temática sería recuperada con el fin de profundizar y, a la vez, de concientizar a las mujeres de que existía una «igualdad divina» que ameritaba que batallaran en pos de conseguir una real igualdad de género. Por supuesto, habría que reforzar dicha posición ante los incesantes «embates masculinos». Allí, la encargada de la nota, tan convincentemente como le era posible, manifestaba: «... nos va llegando el tiempo de hacerles sentir de un modo irresistible que conocemos nuestra posición. Nosotras defenderemos nuestros derechos, y también cantaremos el triunfo de la libertad. La religión santa no ha impuesto la menor diferencia entre los deberes de dos esposos y los hombres han establecido una muy grande» (LA, 27/2/1831, p. 10).

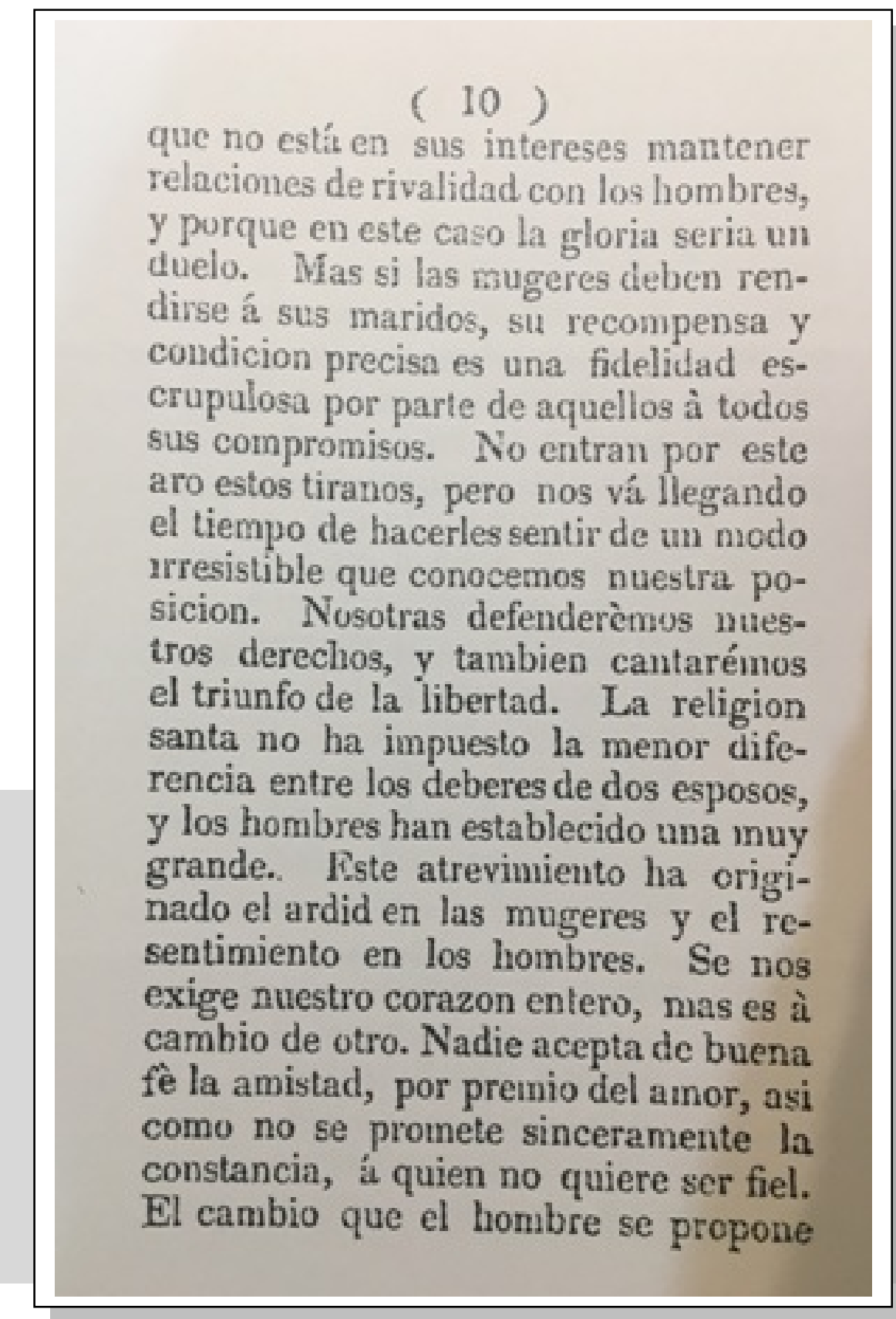

La Argentina, 27 de febrero de 1831, p. 10 


\section{Política}

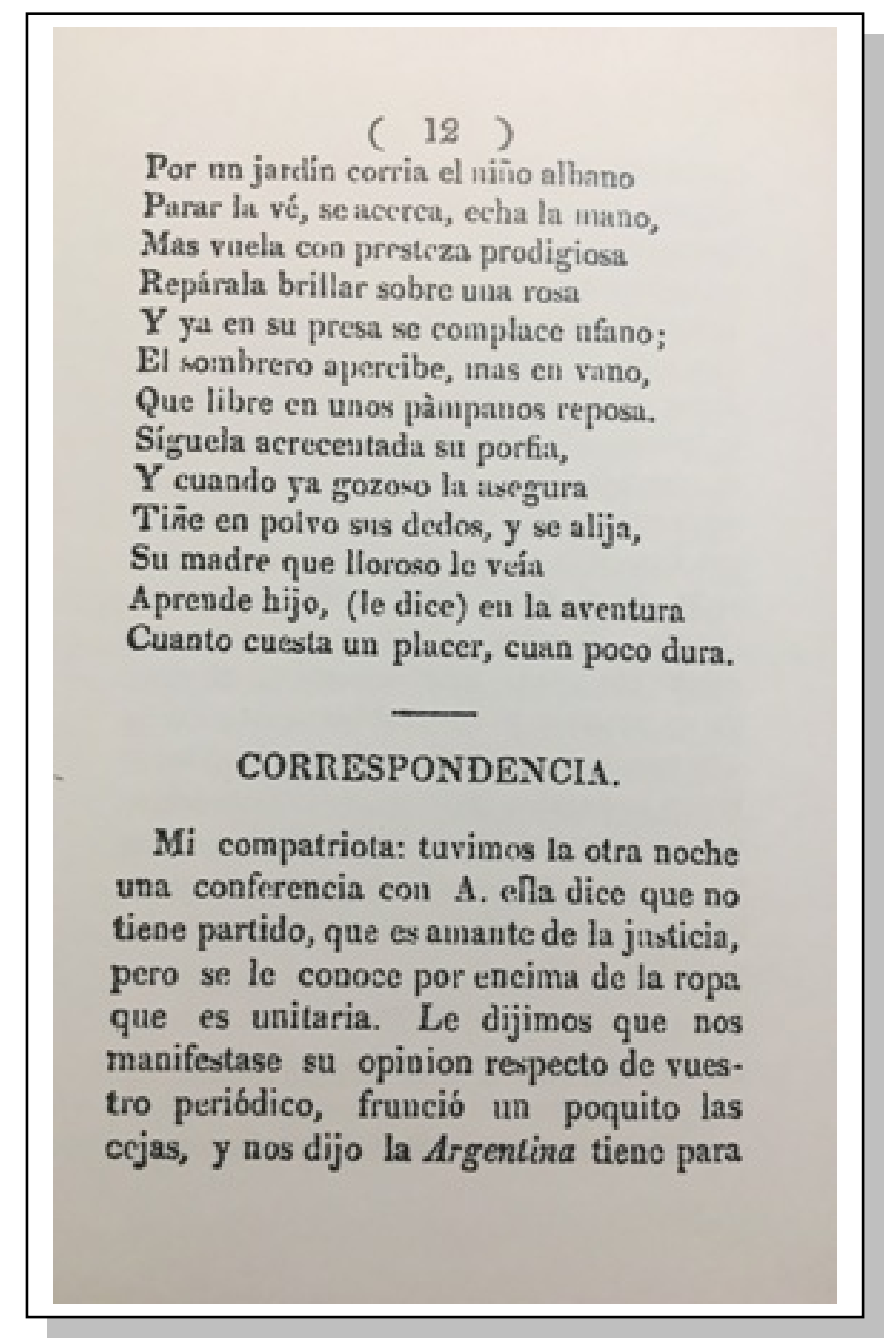

La Argentina, 18 de enero de 1831, p. 12

Acaso un buen ejemplo para ilustrar el novedoso y polémico perfil de la publicación sea la correspondencia en la que se podía leer: «Mi compatriota: tuvimos la otra noche una conferencia con A., ella dice que no tiene partido, que es amante de la justicia, pero se le conoce por encima de la ropa que es unitaria. Le dijimos que nos manifestase su opinión respecto de vuestro periódico, frunció un poquito la ceja, y nos dijo La Argentina tiene para mí un defecto, y es que está muy metida en política. Las mujeres no debemos entender en estas cosas. Le contestamos que se equivocaba, y que principalmente en nuestro país no puede haber una sola persona que no sea política, porque desde los hombres hasta los niños de pecho no oyen otra conversación todo el día» (LA, 18/1/1831, pp. 12-13). Característica esta que el medio supo capitalizar a favor de una reconsideración para las mujeres y que formaba ya parte del espíritu de época. Por supuesto que la posición adoptada por este semanario femenino provocaba rechazo, sobre todo, en los hombres y, muy especialmente, en aquellos adscriptos a la fracción unitaria. 


\section{( 13$)$}

rii un deferto, y es que estí muy metida on política, Las mugers's no debemos entender en estas cosas. Le contestaınos que se eqquirocaba, y que principalmente en nuestro pais no puede haber una sola persoua que no sea politica, porque desde los hombres, hasta los viños de pecho no oyen otra conversacion todo el dia. Como es $\tan$ floja le pronetimos publicar su opiuion para que voz la scpais, y cuaudo sc oîrezca ocasion le deis una. buena carga.

Es vuestra Amiga-

$M$.

\section{PESAME.}

La Argcntina siente haber sido causa inmediata, de la temprana mucrte de ladecrépita ALIADA. ¿Quién pudria imaginar que la crítica de un soncto pudicse ocasionar tantos estragos on un corrzon tan càndido, que solo se complacía en contemplar las obras de la Providencia?

La Argentina, 18 de enero de 1831, p. 13 


\section{Referencias}

Auza, N. (1988). Periodismo y feminismo en la Argentina 1830-1930.

Buenos Aires, Argentina: Emecé.

Auza, N. (2004). La Aljaba. Dedicada al bello sexo argentino 1830-1831

[Estudio preliminar]. La Plata, Argentina: Archivo Histórico de la

Provincia de Buenos Aires / Instituto Bibliográfico Antonio Zinny.

Batticuore, G. (2005). La mujer romántica. Lectoras, autoras y escritores

en la Argentina: 1830-1870. Buenos Aires, Argentina: Edhasa.

Díaz, C. L. (2011). La Argentina 1830-1831. Edición facsimilar [Estudio

Preliminar]. La Plata, Argentina: Instituto Cultural de la Provincia de

Buenos Aires.

Rosenblat, Á. (1964). El nombre de la Argentina. Buenos Aires, Argentina: EUDEBA.

Sosa de Newton, L. (1986). Diccionario biográfico de mujeres argentinas.

Buenos Aires, Argentina: Plus Ultra.

Nota

1 Esta autora, además, incurre en el error de establecer a La Argentina como sucesora de La Aljaba: «Esta vez por un hombre que adopta la voz de una mujer. Manuel de Irigoyen es el director y redactor (travestido) de La Argentina, que el domingo 28 de noviembre de 1830, es decir, algunos pocos días después de la aparición de La Aljaba...» (Batticuore, 2005, p. 120). 